\section{Elements of disaster}

\section{John B. Whittow}

Volcanic Hazards: A Sourcebook on the Effects of Eruptions. By R.J. Blong. Academic: 1984 . Pp.424. \$66, £49.50.

IN A period when such environmental disasters as drought in Ethiopia and flood in Bangladesh make headline news, it has now been generally acknowledged that many Third World communities have become so "marginalized" that the slightest aberration in their local atmospheric or geophysical systems may trigger a disaster. Records suggest that there has been no increase in either the magnitude or the periodicity of hazardous events, but death tolls continue to rise. ficant trend, however, for while the loss of life from natural disasters has increased in the developing world, deaths in the developed world have fallen. Most observers claim that the dichotomy results from the "technological cushion" enjoyed by developed nations, where scientific knowledge, organized planning and advanced warning systems have combined to alleviate the threat and ease the impact of natural hazards. Critics highlight the distinction between those societies which can choose from a long list of structural and non-structural adjustments and those which have no choice. The latter have limited expertise and local infrastructure, little or no opportunity to insure against disaster, and even if warnings could be disseminated the lack of mobility inhibits evacuation: they must bear the loss of life and property.

Any new publication dealing with natural hazards must be viewed in this light. Increasingly, the value of such books is judged by the degree to which they offer to help reduce the vulnerability of threatened populations, whatever their economic or social status; it is no longer enough simply to catalogue and explain the physical phenomena of natural hazards. One is encouraged, therefore, to discover that Volcanic Hazards has this humanitarian concern as one of its three aims. Its other objectives, of chronicling and analysing the effects of the hazard, follow the traditional approaches adopted by the plethora of books on the subject which have appeared over the past decade.

Volcanic hazard research has progressed far beyond such pioneering works as Symons and Lacroix who, respectively, described the famous eruptions of Krakatau and Mont Pelée almost a century ago. Even the modern global syntheses of Bullard ${ }^{1}$ and Francis ${ }^{2}$ have rapidly

been overtaken as earth scientists have become more concerned with effects than with causes. Following the valuable work of Walker ${ }^{3}$ on volcanic prediction, and of Sheets and Grayson ${ }^{4}$, who examined the relationship between volcanoes and human ecology, there has been an urgent need for a single volume that would bring together the mass of literature on volcanic eruptions in a clear and concise form. R.J. Blong has provided such a volume. Here is a well-written "sourcebook" (the author's own subtitle) which not only examines all of the well-chronicled volcanic events from Santorini $(1500 \mathrm{BC})$ to Mount St Helens (AD 1980), but also provides, at the end of each chapter, an appraisal of the impact of volcanic activity on various aspects of the environment.

In Blong's assessment of deaths and injuries caused by volcanic eruptions, several points emerge. For instance, 